\title{
Living recovery
}

Received 3 March 2012; Accepted 5 March 2012; First published online 22 May 2012

Key words: Human rights, non-linear process, recovery, service user involvement.

Commentary on: Slade et al. (2012). International differences in understanding recovery: systematic review. Epidemiology and Psychiatric Sciences (doi:10.1017/S2045796012000133).

By expanding on their earlier review of published literature, Slade et al. provide a valuable service by examining the presence and nature of policies and conduct of research related to recovery across the globe. Their findings, while not surprising, are useful in gauging the progress to date of different countries in embracing the concept of personal recovery as a foundation for mental health policy. In addition to pointing out how this concept has largely been developed and remained within the confines of the English-speaking world, they wisely suggest that, as recovery begins to seep into non-English speaking countries, it is important that the translation of this concept be a 'two-way process'. By this, the authors argue that 'research from culturally more dissimilar countries would help to highlight both embedded social and political assumptions about the nature of recovery, and the individualistic rather than collectivist focus of current models'. Such a reciprocal process might help to address concerns that the authors noted among the service-user community in the English-speaking world that recovery has come to focus too much 'on the adjustment of the individual to social forces'.

In this respect, I have no reason to question the findings of this review and, in fact, wish to underscore Slade et al. recommendation that service users and carers be afforded substantive roles in moving the concept of recovery forward in both policy and practice arenas. Where I differ is in my assessment of the importance of this role for service users, in particular, in bringing the field to where it is today. Certainly in

Address for correspondence: L. Davidson, Ph.D., Professor of Psychiatry and Director, Program for Recovery and Community Health, Yale PRCH, Building 1, Erector Square, 319 Peck Street, New Haven, CT 06513, USA.

(Email: larry.davidson@yale.edu) the USA, and I believe to a significant extent in Europe as well, the introduction and dissemination of the concept of personal recovery have been primarily the result of the efforts of service users - rather than those of researchers, practitioners, or policy-makers. It therefore is curious that in the list of possible reasons for the 'uneven policy endorsement' of recovery, Slade et al. do not even consider the role of service users. They consider, instead, 'the absence of any mental health-specific policy in some countries; an opposition to a recovery orientation in principle; and an absence of recovery research relevant to the specific country'. What they do not appear to consider is the presence and the role of an empowered service user community in advocating for their individual and collective civil rights as citizens of their respective societies. However, I suggest that this is at least as important a factor, if not more so, than any of those listed above in accounting both for the 'uneven policy endorsement' of recovery and the amount of funding and effort devoted to conducting research related to recovery in the countries surveyed.

Rather than through policy-makers or researchers those stakeholders emphasized by Slade et al. - it has been my impression that the concept of personal recovery has spread its influence across the globe primarily through the activation, organization and advocacy efforts of the service-user movement. That is, endorsement of the concept of personal recovery in the policy and research arenas can be viewed as more similar to that of HIV/AIDS than that of the community mental health movement in the 1950s and 1960s or the introduction of a new surgical technique, medication, or psychotherapy in the 21st Century. The concept of personal recovery is not itself an 'evidence-based practice', and need not be made into one in order for its influence to continue to spread. It has been and continues to be rather a matter of human rights (Chamberlin, 1978; Deegan, 1992; Davidson, 2006), and was initially established and claimed as such by those persons most affected by the conditions from which they are recovering. As in the case of HIV/AIDS, strenuous advocacy 
has been more responsible for changes in policy and for making funding availability for research on the condition a societal priority than the other way around. And we have every reason to believe that this has been and will continue to be the case in the future for further development and spread of the recovery movement.

In this respect, I believe that Slade et al. may be underestimating the central role that the service-user community has played, and needs to continue to play, in developing the scientific evidence base for the concept of personal recovery and for the effectiveness of new interventions created to promote personal recovery. We owe the concept of personal recovery to persons with serious mental illnesses who decided that they need not wait until they were 'cured' of the condition by others in order to pursue a meaningful and self-determined life through which they could make valuable contributions to the society. We must be very cautious in bringing this concept into the scientific arena, and make whatever efforts are necessary to ensure that the concept does not become something very different in the hands of persons who do not share this body of first-hand experience. While service-user collaboration and co-production of research are certainly important steps in this direction (and significant improvements over having service users simply advise or consult), there also is a growing body of service user-led research (e.g., Wallfcraft et al. 2009), which may prove to be more important in the long-run in ensuring that evidence is collected on personal recovery that does not transform it de facto into clinical recovery.

Attempting to conceptualize what we have been told is a non-linear process on the basis of a linear stage model is only one example of how the use of conventional science may distort, rather than develop evidence for the nature of this particular form of recovery. Just because the trans-theoretical model of change has been extremely useful in understanding and promoting recovery in addiction is not sufficient reason to apply it to personal recovery. Addiction recovery requires the behavioural changes involved in learning how to choose not to use alcohol or illicit substances. There is no parallel role for behaviour change or choice in the case of serious mental illness (Davidson et al.
2010). I cannot choose to stop hearing voices, to stop becoming depressed, or to stop having delusional thoughts. Pursuing recovery in the face of a serious mental illness involves many more factors in addition to those that take place within the individual, including such things as social support, access to material and instrumental resources, and opportunities for occupying valued social roles. Personal choice plays a very limited role, especially when the person has very limited, if any, choices to begin with. If we are to develop a more thorough and deeper understanding of this form of recovery, and develop innovative and effective interventions to promote it, the service-user community will need not only to partner with researchers, but will need to take the lead in ensuring that we do not simply find a new way to oppress, marginalize and blame persons with serious mental illnesses for their plight. Should we do so, we can expect that the unfortunately legitimate concern of the service-user community described in Slade et al.'s report will only become more persistent and pronounced, and, as a result, more likely to discourage funding for research than to support it.

L. Davidson

Professor of Psychiatry and Director, Program for Recovery and Community Health, Yale University School of Medicine, New Haven, USA

\section{References}

Chamberlin J (1978). On Our Own: Patient-controlled Alternatives to the Mental Health System. Hawthorn Books: New York.

Davidson L (2006). What happened to civil rights? Psychiatric Rehabilitation Journal 30, 11-14.

Davidson L, Roe D, Andres-Hyman R, Ridgway P (2010). Applying Stages of Change models to recovery in serious mental illness: contributions and limitations. Israel Journal of Psychiatry 47, 213-221.

Deegan PE (1992). The independent living movement and people with psychiatric disabilities: taking back control over our own lives. Psychosocial Rehabilitation Journal 15, 3-19.

Wallcraft J, Amering M, Schrank B (Eds.) (2009). Handbook of Service User Involvement in Mental Health Research. Wiley: London. 